\title{
A COMPARISON OF THE SHEAR BOND STRENGTHS OF \\ TWO GLASS IONOMER CEMENTS
}

\author{
by \\ Michael Patrick Meehan, D.D.S.
}

Division of Graduate Orthodontics

Submitted in partial fulfilment

of the requirements for the degree of Master of Clinical Dentistry

Faculty of Graduate Studies The University of Western Ontario London, Ontario

February 1997

OMichael Patrick Meehan 1997 
National Library

of Canada

Acquisitions and Bibliographic Services

395 Wellington Street Ottawa ON K1A ON4 Canada
Bibliothèque nationale du Canada

Acquisitions et services bibliographiques

395, rue Wellington OHawa ON K1A ONM Canada
Your fis varentirenes

Our fis Node ritine
The author has granted a nonexclusive licence allowing the National Library of Canada to reproduce, loan, distribute or sell copies of his/her thesis by any means and in any form or format, making this thesis available to interested persons.

The author retains ownership of the copyright in his/her thesis. Neither the thesis nor substantial extracts from it may be printed or otherwise reproduced with the author's permission.
L'auteur a accordé une licence non exclusive permettant à la Bibliothèque nationale du Canada de reproduire, prêter, distribuer ou vendre des copies de sa thèse de quelque manière et sous quelque forme que ce soit pour mettre des exemplaires de cette thèse à la disposition des personnes intéressées.

L'auteur conserve la propriété du droit d'auteur qui protège sa thèse. $\mathrm{Ni}$ la thèse ni des extraits substantiels de celle-ci ne doivent être imprimés ou autrement reproduits sans son autorisation. 


\begin{abstract}
The objective of this study was to determine the in vitro shear bond strength (MPa) and location of bond failure using two light-cured glass ionomer resin systems. These systems, Fuji Ortho LC (GC Orthodontics) and Ultra Band Lok (Reliance) were compared to a light-cured composite resin. Maxillary premolar brackets $(n=200)$ were bonded to the facial surface of human premolar teeth. The two glass ionomer resin systems were each evaluated by two protocols, one according to the manufacturers' direction plus a variation of their respective technique. The five distinct groups $(n=40)$ were stored in $37^{\circ} \mathrm{C}$ distilled water for 30 days and subjected to thermocycling prior to shear bond strength testing.

The findings indicated that large variations existed between the bond strengths of the materials tested. The laboratory shear bond strength of the Reliance Ultra Band Lok, whether tested in a dry or moist field, was similar to the composite control with all being significantly ( $p<0.01$ ) higher than both Fuji Ortho LC groups. However, the Fuji Ortho LC with enamel conditioner demonstrated a clinically acceptable mean MPa value. The Adhesive Remnant Index (ARI) values ranged from 0.53 to 1.62 . The Fuji Ortho LC without enamel conditioning recorded the lowest mean ARI score and the lowest mean MPa score.

Although both products are glass ionomer resin systems, their individual chemistries vary which may influence their bond strengths. Clinically, it may be suggested that glass ionomers used in a dry field may be beneficial for orthodontic bonding and glass ionomer resin systems used in a moist environment need an enamel conditioner.
\end{abstract}

Keywords: Glass Ionomer Cements, Orthodontic Bonding, Shear Bond Strength 


\section{ACKNOWLEDGEMENTS}

I would like to express my gratitude to the members of my thesis committee: Dr. Tim Foley, Dr. Antonios Mamandras, Dr. David Banting, Dr. Bruce Fill and Dr. K.A. Galil for their constructive input.

In particular, thanks to Dr. Tim Foley for his dedication and support throughout the course of this project.

I wish to acknowledge P.J. Blake for her assistance in the preparation of the written component of this document and Dr. Gail Chow for her assistance in the collection of the data.

Thank you to my classmates, Dr. Paul Karl and Dr. Pius Kim, for their companionship and support during our residency. You have made this a wonderful experience.

To my parents, who made many sacrifices so that I could achieve my education. Thank you for reminding me that I could become whatever I wanted to become.

To my wife, Debbie, who has always put my professional goals ahead of her own; thank you for your love and support. To my son, Patrick, you could not have entered our lives at a better time. You and your mom help to keep my professional life in perspective. 


\section{TABLE OF CONTENTS}

Page

Certificate of Examination $\ldots \ldots \ldots \ldots \ldots \ldots \ldots \ldots \ldots \ldots \ldots \ldots \ldots \ldots$

Abstract $\ldots \ldots \ldots \ldots \ldots \ldots \ldots \ldots \ldots \ldots \ldots \ldots \ldots \ldots \ldots \ldots \ldots$ iii

Acknowledgements $\ldots \ldots \ldots \ldots \ldots \ldots \ldots \ldots \ldots \ldots \ldots \ldots \ldots \ldots \ldots \ldots$ iv

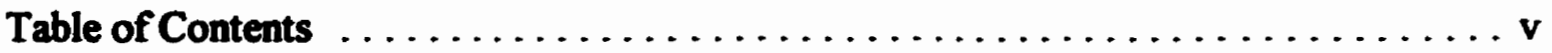

List of Tables $\ldots \ldots \ldots \ldots \ldots \ldots \ldots \ldots \ldots \ldots \ldots \ldots \ldots \ldots \ldots \ldots$

List of Figures $\ldots \ldots \ldots \ldots \ldots \ldots \ldots \ldots \ldots \ldots \ldots \ldots \ldots \ldots \ldots$

List of Appendices $\ldots \ldots \ldots \ldots \ldots \ldots \ldots \ldots \ldots \ldots \ldots \ldots \ldots \ldots$ viii

Introduction $\ldots \ldots \ldots \ldots \ldots \ldots \ldots \ldots \ldots \ldots \ldots \ldots \ldots \ldots \ldots \ldots$

Materials and Methods $\ldots \ldots \ldots \ldots \ldots \ldots \ldots \ldots \ldots \ldots \ldots \ldots \ldots$

Results $\ldots \ldots \ldots \ldots \ldots \ldots \ldots \ldots \ldots \ldots \ldots \ldots \ldots \ldots \ldots \ldots \ldots$

Discussion $\ldots \ldots \ldots \ldots \ldots \ldots \ldots \ldots \ldots \ldots \ldots \ldots \ldots \ldots \ldots \ldots \ldots \ldots \ldots$

Summary and Conclusions $\ldots \ldots \ldots \ldots \ldots \ldots \ldots \ldots \ldots \ldots \ldots \ldots \ldots$

Tables $\ldots \ldots \ldots \ldots \ldots \ldots \ldots \ldots \ldots \ldots \ldots \ldots \ldots \ldots \ldots \ldots \ldots \ldots$

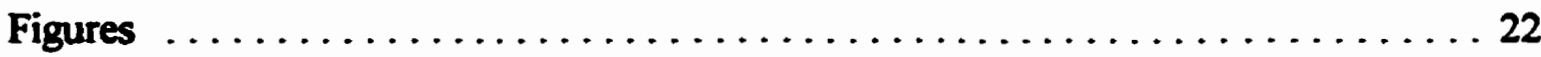

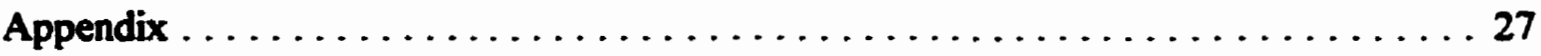

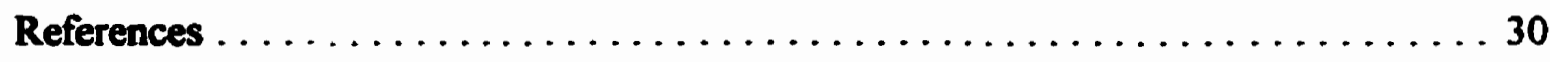

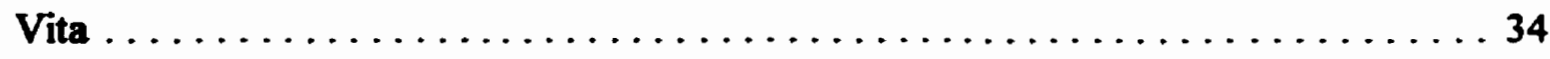




\section{LIST OF TABLES}

Table

$$
1
$$

2

3

4
Description

Page

Shear Bond Strengths (MPa)

18

Mean Difference (MPa) and Statistical Significance as Determined by Multiple Comparison

19

ARI Scores

20

Multiple Comparison Z-values and Statistical

Significance 


\section{LIST OF FIGURES}

Figure

Description

Page

1

Ultra Band Lok glass ionomer cement

22

2

Fuji Ortho LC glass ionomer cement

22

3

Transbond orthodontic bonding material

23

4

A sample placed in the Thermocycle unit

23

Premolar tooth with bonded bracket in an acrylic block secured in vice

Mean Shear Bond Strengths

25

Mean ARI Scores

26 


\section{LIST OF APPENDICES}

Appendix

1
Description

Page

Shear Bond Strengths (kg, MPa) and Adhesive Remnant Index (ARI) Scores for all Specimens 


\section{INTRODUCTION}

A significant change in orthodontics over the last twenty years has been the replacement of cemented bands by bonded orthodontic brackets. The development of the acid etch technique ${ }^{1}$ has led to the bonding of orthodontic brackets with composite resins ${ }^{2}$, which improves esthetics, greatly reduces chairside time and makes oral hygiene easier for the patient. Although technique sensitive, the development of composite resins has enabled the placement of orthodontic brackets with bond strengths that resist masticatory forces. The literature ${ }^{3-7}$ has reported that the bond strength values for adhesion vary somewhat, however values greater than 5 Megapascals are suggested to be adequate for bonding.

Etching of the enamel prior to bonding provides a strong mechanical bond of the composite resin to the enamel rods.' However, previous studies ${ }^{2-12}$ have shown that this increase in shear bond strength may come at the expense of the outer layer of enamel. Localized enamel fractures created during debonding procedures have been attributed to the micromechanical retention produced from acid etching treatment. ${ }^{10-13}$ Although Zachrisson et al ${ }^{13}$ found that a sample of orthodontically treated teeth had a significantly higher $(p<0.05)$ prevalance of enamel cracks than did a nontreated sample, he suggested that careful debonding does not result in a significant increase of enamel cracks.

In the absence of good oral hygiene and fluoride treatments, dimineralization can occur rapidly around bracket margins. ${ }^{14}$ Gorelick et al $^{15}$ studied the incidence of decalcification following fixed orthodontic treatment and found a significant increase after debanding. The control group of fifty children showed 24 of the cases to have 
demineralization on one or more of the teeth. Of the control's 1006 teeth examined, $3.6 \%$ showed decalcification. This was compared to $49.6 \%$ of a sample of 121 randomly selected patients who after debonding had a white spot lesion on at least one tooth and of the total of 2211 teeth examined, $11 \%$ showed decalcification.

Unlike resin-filled composites, glass ionomer cements (GICs) adhere to unetched enamel by physiochemical means and do not remove the fluoride-rich outer layer. This adherence is based on molecular interactions between the calcium ions in the enamel and the carboxyl groups of the GIC. ${ }^{16,49}$ Glass ionomer cements also have the benefit of being a longterm, low-concentration fluoride-releasing agent. ${ }^{17}$ Hallgren et al $^{17}$ tested the fluoride concentration in plaque adjacent to orthodontic appliances that were retained with GIC and composite cement. After 3 days, the plaque taken from around the GIC bonded brackets showed fluoride concentrations that were 44 times higher than that taken around composite bonded brackets. Although the fluoride concentration decreased significantly from 3 days to 6 months, an 11-fold difference was still present between the two cements at 6 months. Hallgren et al, ${ }^{18}$ in a similar study, compared the $L(+)$-lactic acid production in plaque around brackets bonded with both GIC and composite resin. The plaque around brackets bonded with the GIC showed significantly $(p<0.05)$ less acid production. Fluoride releasing GICs create a "zone of inhibition" on the enamel surrounding the bracket. ${ }^{17}$ GICs have also shown a less effected enamel surface after debonding. ${ }^{19}$

A drawback between composite resins and conventional GICs is that GICs show consistently lower bond strengths. ${ }^{20-23}$ Fajen et $\mathrm{al}^{22}$ compared three conventional GIC's to a composite control, and found low bond strengths ranging from 0.84 to $3.91 \mathrm{MPa}$ for the 
GICs compared to $11.27 \mathrm{MPa}$ for the composite resin. Wiltshire ${ }^{23}$ reported mean bond strengths of the unetched and etched samples of GIC of 4.4 and $5.5 \mathrm{MPa}$, respectively, compared to $26 \mathrm{MPa}$ for the composite control. Clinical comparisons of the conventional GICs also show them to be inferior in bond strength to composite resins. ${ }^{24,25}$ In a 12 month trial, Miquel et al ${ }^{24}$ reported bond failure rates of $51 \%$ and $8 \%$ for GIC and composite resin groups, respectively. Miller et al ${ }^{2 s}$ in a three year clinical trial also found that brackets bonded with GIC were more likely to fail $(p<0.022)$.

New generation, resin reinforced, light-cured glass ionomer cements have been reported to be successful in bonding orthodontic brackets. ${ }^{26,27}$ These new resins are of two types: resin incorporated into the glass filler and methylmethacrylate incorporated into the polyacrylic acid. Fricker ${ }^{26}$ bonded 10 cases (120 teeth), half of each malocclusion with a composite resin and the other half with a resin-modified light-activated GIC. After 12 months the GIC group had 2 debonds as compared to one debond for the composite group. Silverman et $\mathrm{al}^{27}$ bonded 150 cases also using a new generation GIC and claimed a $96.8 \%$ success rate in which many second molars were included.

The in-vitro studies to date have shown that resin reinforced GICs retain brackets significantly better than conventional GICs. ${ }^{22-31}$ Ewoldsen et al ${ }^{31}$ tested the effects of various methods of enamel conditioning on bond strengths using a resin reinforced GIC and compared them to a composite control. Four of the five GIC subgroups (no conditioning, 10\% polyacrylic acid, 37\% phosphoric acid, and PA-HEMA copolymer primer) were not statistically significant from one another. Only the human saliva contaminated group was significantly weaker $(p<0.05)$. The four non-significant GIC groups ranged in bond strengths 
of 6.51 - 7.95 MPa. However, all of the GIC groups were significantly less $(p<0.05)$ in bond strength when compared to the composite resin (10.39 MPa). If the resin-reinforced GICs exhibit bond strengths suitable for the bonding of orthodontic brackets, then their advantages over composite resins make them the product of choice. The two cements selected for this study are Fuji Ortho LC ${ }^{\wedge}$ and Ultra Band Lok: The Fuji cement is a resin-reinforced, water based, dual cure cement which the manufacturer claims can be used without the need of acidconditioning. Light-curing activates free radical polymerization of HEMA and two other monomers, to form a poly-HEMA matrix, thus, immediately setting the material. The Ultra Band Lok is a photoinitiated, resin base cement which uses a 3 second non-phosphoric acid conditioner to create a larger surface area to bond to the enamel. The conditioner is followed by the placement of a photoinitiated BIS GMA hydrophilic sealant.

The purpose of this study is to compare the shear bond strengths of the two lightcured glass ionomer cements to a composite control. In addition, the clinical value will further be assessed by determining the location of bond failure after debonding.

GC Orthodontics, Aslip, $\mathbf{L}$

'Reliance Orthodontic Products, Inc., Itasca, IL 


\section{MATTRIALS AND MITHODS}

Bonding of brackets to premolars:

Two hundred extracted human premolar teeth were divided into five groups of forty. Fuji Ortho LC and Ultra Band Lok were tested using the manufacturers' recommendation plus a technique variation and compared to the control composite, Transbond XT". Each bicuspid bracket was bonded using an Ortholux XT" standard curing light at a curing distance of $1 \mathrm{~mm}$ or less. The curing light was calibrated every 10 minutes to ensure a proper wavelength of above $400 \mathrm{~nm}$. The five groups $(n=40)$ were bonded as follows:

\section{Ultra Band Lok, GIC (No Moisture) (Fig 1)}

Each tooth was rinsed and dried after a pumice polish. With a brush, the tooth conditioner ${ }^{\circ}$ was applied to the enamel. Three seconds later the conditioner was dried with air. A coat of the hydrophilic sealant ${ }^{\circ}$ was painted on the conditioned tooth, allowed to sit for 10 seconds, lightly dried with air and then light cured for 10 seconds. The Ultra Band Lok paste was applied to the bracket base and positioned on the tooth. It was light cured for 20 seconds from the incisal edge of the bracket and 20 seconds from the gingival bracket edge.

\footnotetext{
3M/Unitek Company, Minneapolis, MN

"A" Company, Micromesh .022 Roth Rx., San Diego, CA

${ }^{o}$ Reliance Orthodontic Products, Inc., Itasca, IL.
} 


\section{Ultra Band Lok, GIC (Moistened)}

Each tooth was rinsed and dried after a pumice polish. With a brush, the tooth conditioner was applied to the enamel. Three seconds later, the conditioner was dried with air. The surface was moistened with a water-soaked gauze. A coat of the hydrophilic sealant was painted on the conditioned tooth, allowed to sit for 10 seconds, lightly dried with air and then light cured for 10 seconds. The Ultra Band Lok paste was applied to the bracket base and positioned on the tooth. It was light cured for 20 seconds from the incisal edge of the bracket and 20 seconds from the gingival bracket edge.

\section{Fuji Ortho LC, GIC (No Conditioner) (Fig 2)}

Each tooth was left moist after a pumice polish and thorough water lavage. The bracket was then placed on the enamel surface with the GIC adhesive and light cured for 20 seconds from the incisal edge and 20 seconds from the gingival bracket edge.

\section{Fuji Ortho LC, GIC (With Conditioner)}

Each tooth was rinsed and dried after a pumice polish. A $10 \%$ polyacrylic acid was placed on the tooth for 20 seconds. The tooth was left moist following a thorough water lavage. The bracket was then placed on the enamel surface with the GIC adhesive and light cured for 20 seconds from the incisal edge and 20 seconds from the gingival bracket edge. Trandsbond XT (control) (Fig 3)

Following the mamufacturer's directions, the brackets were bonded to the teeth. The enamel surface was rinsed and dried after a pumice polish, followed by a 60 second acid etch with $37 \%$ phosphoric acid " and then each tooth had a thorough water lavage. The bonding

\footnotetext{
3M/Unitek Company, Minneapolis, MN
} 
agent ${ }^{n}$ was light cured for 10 seconds. The bracket was placed on the enamel surface with the Transbond composite adhesive and light-cured for $\mathbf{4 0}$ seconds.

Storage:

The teeth were allowed to bench set for 15 minutes before being placed into a $100 \%$ humidor for 24 hours. They were then transferred to an incubator of distilled water and stored for $\mathbf{3 0}$ days. Following water storage, the specimens were then further stressed by thermocycling which consisted of two thermally controlled streams of water maintained at $10^{\circ} \mathrm{C}$ and $55^{\circ} \mathrm{C}$. Each cycle lasted for one minute $\left(30\right.$ seconds at $10^{\circ}$ and 30 seconds at $55^{\circ} \mathrm{C}$ ). 1500 cycles were completed over a period of 24 hours. (Fig 4)

Debonding:

Each specimen was placed in a custom acrylic block which approximated the height of normal bone. There was special emphasis on securing the block in a vice in a position that would place the facial surface of each premolar parallel to the plunger of the testing machine. (Fig 5) This allowed the plunger to be perpendicular to the bracket. Each premolar bracket had a segment of a $21 \times 25$ stainless steel wire ligatured in the bracket slot to prevent the debonding machine from deforming the bracket during debonding. The brackets were debonded using a shear load on an Instron Universal Testing machine.“ A $50 \mathrm{~kg}$ load cell was applied on each bracket at a cross-head speed of $0.5 \mathrm{~mm} / \mathrm{min}$. The kilogram value was divided by the bracket base size $\left(13.564 \mathrm{~mm}^{2}\right)$ to give a reading in $\mathrm{kg} / \mathrm{mm}^{2} . \mathrm{Kg} / \mathrm{mm}^{2}$ was then

“Instron Corp., Canton, MA 
converted to megapascals (MPa) by multiplying by 9.81 .

Bond failure was assessed by examination of the bracket bases and the debonded enamel surfaces using a $10 \mathrm{X}$ illuminated magnifying lens. The debonded surfaces were evaluated using the Adhesive Remnant Index (AR) ${ }^{47}$ which quantifies the amount of adhesive remaining on the bonded surface following debonding. A score of 0 indicates no adhesive was left on the enamel, $I$ indicates less than half of the adhesive remained on the enamel, 2 indicates more than half of the adhesive remained on the enamel, and 3 indicates all of the adhesive was left on the enamel. Debonds that resulted in enamel fracture were eliminated from the ARI evaluation.

Statistical Analysis:

To determine the statistical significance in shear bond strengths between the five groups, the mean MPa values were analyzed using one-way ANOVA. Tukey's Test at a 5\% level of significance was used to determine specific pairwise group differences. The significance of the difference between the five groups of ARI data were analyzed using the Kruskal-Wallis one-way ANOVA and multiple comparisons. 


\section{RISULTS}

The distribution of the MPa data from all five groups showed high intersample variation. Subsequently the non-symmetrical data was normalized by using a square-root transformation $\left(x^{1}=x^{0.5}\right)$, and statistical analysis was performed using these transformed values. The mean and median Megapascals, standard deviations and the range of shear bond strengths for the five groups are listed in Table 1 and displayed graphically in Figure 6. At least two of the means were statistically different among the five bonding systems (one-way ANOVA, $F_{4193}=32.85, p=0.0001$ ). The bond strengths of the two Ultra Band Lok groups were not significantly different from the Transbond control group (Table 2). The Ultra Band Lok group in which the manufacturer's recommendations were followed, showed a higher mean bond strength than the Transbond control, with scores of 11.36 and 11.23 , respectively. These three groups showed mean shear bond strengths that were significantly higher than those of the Fuji Ortho LC groups $(p<0.01)$. The Fuji Ortho LC without enamel conditioning, produced a significantly lower mean bond strength than the other four groups $(p<0.001)$. Only the Fuji Ortho LC without conditioner did not achieve a clinically acceptable bond strength of above $5 \mathrm{MPa}$.

The mean ARI scores, standard deviations and range for the five groups are listed in Table 3 and displayed graphically in Figure 7. The means were statistically different among the five bonding systems tested (Kruskal-Wallis one-way ANOVA, $x_{4}^{2}=55.90, p<0.0001$ ). The Ultra Band Lok group in which the manufacturer's recommendations were followed (group 1) and the Fuji Ortho LC with enamel conditioning (group 4) showed the highest 
mean scores of 1.62 and 1.44 , respectively, indicating that they were approaching the level where bond failure occurs at the bracket/adhesive interface. The difference between these two groups were statistically different from groups 2,3 , and 5 ( $p<0.05$ ) (Table 4). Fuji Ortho LC without conditioner (group 3) recorded a mean score of 0.53 indicating a bond failure at the enamel/adhesive interface. This group was not statistically different from the next two higher scores (groups 2 and 5). 


\section{DISCUSSION}

The replacement of banding with bonding has reduced the use of separators, conserved arch perimeter, facilitated oral hygiene and esthetics, and eliminated the need for band-space closure during the retention stage of treatment. ${ }^{2}$ However, acid etching impacts upon the outer enamel layer ${ }^{2-12}$ and may potentially create decalcification. ${ }^{14,15,32}$

A viable alternative to the traditional acid etch technique, provided bond strength is adequate, is the use of resin reinforced glass ionomer cements. These cements can chemically adhere to both enamel and metal ${ }^{33}$ and they release fluoride and subsequently may help prevent demineralization. ${ }^{17}$ The fluoride content of enamel adjacent to brackets bonded with glass ionomer cements is increased. ${ }^{34}$ However, the fluoride uptake may be variable with resin reinforced GICs. Also, GICs have been shown to debond through dessication from air drying potentially making debonding easier ${ }^{35}$ and have shown a less affected enamel surface after debonding. ${ }^{19}$

The present study showed that the Ultra Band Lok GIC groups were not significantly different in shear bond strength from the Transbond control group, and these three groups were significantly stronger $(p<0.01)$ when compared to the two Fuji Ortho LC groups. However, the Fuji Ortho LC with conditioner displayed clinically acceptable bond strength values. The two glass ionomer cements have different chemical make-ups which may contribute to their differences in shear bond strength. The Fuji Ortho LC is a resin reinforced water based GIC whereas the Ultra Band Lok GIC is a composite filled with glass ionomer powder (also known as compomer). ${ }^{36}$ The Fuji Ortho LC consists of fluoroalumino-silicate 
glass, and a liquid that contains polyacrylic acid, a water soluble monomer (hydroxyethyimethacrylate), an activator, and water as the base of the cement. The resin, in which HEMA is the major constituent, makes up approximately $11.25 \%$ of the mixed product. $^{37}$ The Ultra Band Lok GIC, being a glass filled composite with $33 \%$ resin, introduces some controversy in whether it should be classified as a GIC or composite resin and its chemistry may help to explain why the bond strength was similar to the Transbond composite control. The superior adhesion and physical properties in Ultra Band Lok are attributed to the acidic difunctional monomer and the increased percentage of resin. ${ }^{36}$ The resin content strengthens GICs by making them more flexible unlike the brittleness seen in conventional non-resin filled GICs. The resin content also makes GICs much less susceptible to dehydration and less soluble in intra-oral fluids with a stronger bond both cohesively and adhesively. ${ }^{37}$

The Ultra Band Lok group that simulated moisture contamination was not significantly weaker in bond strength than was the Ultra Band Lok group in which the manufacturer's recommendations were followed. The mean shear bond strength of the former was $10.03 \mathrm{MPa}$ and11.36 $\mathrm{MPa}$ for the latter, which may be attributed to the hydrophilic sealant which is a combination of an unfilled resin sealant and Reliances Enhance ${ }^{\mathrm{TM}}$ Adhesion Booster. ${ }^{36}$ No other studies using this material for bonding brackets were found in the literature making comparisons difficult. However, the data suggests that Ultra Band Lok with its higher resin content behaved in a manner similar to a composite.

The mean shear bond strengths of the Fuji Ortho LC were significantly less $(p<0.001)$ than the composite control which is in agreement with other studies. ${ }^{26,20,31,38-41}$ Acid 
conditioning of the enamel prior to bonding produced significantly stronger bond strengths $(p<0.001)$ for the Fuji Ortho LC which concurs with Jaochakarasiri et al ${ }^{38}$ who tested three resin-modified GICs to see the effect of acid etching. The authors ${ }^{39}$ reported a significant $(p<0.001)$ increase in bond strength with acid etching and suggested it was required to achieve adequate bond strengths. Shin and Lee ${ }^{12}$ also found that their sample of resin modified GIC had significantly higher bond strengths to enamel, when a $10 \%$ polyacrylic or a $37 \%$ phosphoric acid solution was used, as compared with a slurry of pumice only. When testing a resin reinforced GIC, Ewoldsen et $\mathrm{al}^{\mathbf{3 l}}$ found no significant differences in shear bond strengths between non-conditioned and conditioned enamel. In fact, the mean bond strengths for the non-conditioned sample was higher at $6.97 \mathrm{MPa}$ as compared to the group in which a $37 \%$ phosphoric acid was used (6.51 $\mathrm{MPa})$. The authors ${ }^{31}$ attributed this to the GIC's ability to chemically bond to the enamel surface and therefore the need for enamel conditioning is eliminated. Carter and $\mathrm{McCabe}^{40}$ reported enamel conditioning to increase bond strengths, but not significantly, for their sample of resin modified glass ionomer cements. The Fuji Ortho LC with conditioner had a significantly $(p<0.001)$ stronger shear bond strength than the unconditioned Fuji group lending strength to the claim $38,40,42$ that acid conditioning of enamel prior to bonding produces stronger bond strengths. Obviously, the use of an enamel conditioner to promote a stronger bond will alter the outer layer of enamel more than if a GIC is used without conditioning.

Millett and McCabe ${ }^{13}$ report that in vitro glass ionomer cements studies typically have large standard deviations in bond strengths values which may create concern over the reliability of both the test system and the bond strength achieved. The data suggests that the 
manipulation of glass ionomer cements is currently technique sensitive in providing optimal bond strengths.

Fox et $\mathrm{al}^{\mathrm{4}}$ suggested that the ideal location for an adequate bond to fail is at the enamel/adhesive interface for this would make bonding and subsequent debonding much easier. In the present study, the non-conditioned Fuji Ortho LC group had a mean ARI score of 0.53 which suggests that little to no adhesive was left on the enamel causing the bond failure at the enameladhesive interface. The regular Ultra Band Lok group and the conditioned Fuji Ortho LC group showed the highest ARI scores, 1.62 and 1.44 respectively. These groups were more likely to have the bond failure between the bracket/adhesive interface. The composite control group and the moistened Ultra Band Lok group had mean ARI scores of 0.84 . The composite control value differed from other studies..$^{31,41,42}$ Scott et $\mathrm{al}^{41}$ and Shin and Lee ${ }^{42}$ found their composite control groups to debond mainly at the bracket/adhesive interface whereas the resin modified GIC groups were more likely to debond at the enamel/adhesive interface. Shin and Lee ${ }^{42}$ reported light-cured GIC bonded to enamel treated with $10 \%$ polyacrylic acid showed less residual materials on the enamel surface than composite resin bonded to enamel etched with $38 \%$ phosphoric acid. Similar to the current study, Nollie et $\mathrm{al}^{\text {ts }}$ determined the fracture site for their composite control group to be principally at the enamel/adhesive interface. The authors ${ }^{45}$ suggest that the increased bond stress placed on the tooth by the $\mathbf{3 0}$ day water storage and the thermocycling may have influenced the fracture site.

Matasa ${ }^{46}$ claimed that the strongest bond with orthodontic adhesive is achieved when the failure is cohesive which means that the adhesive remains on both the enamel and bracket 
in almost equal proportions after debonding. On the ARI scale, this type of bond failure would compute to a mean score between 1 and 2. The regular Ultra Band Lok had an ARI score within this range and also produced the highest mean MPa score which supports the author's ${ }^{46}$ claim. As well, the Fuji Ortho LC without enamel conditioning prior to bonding showed both an adhesive type of bond failure (0.53) and a low bond strength. In contrast, the remaining data did not support Metasa's ${ }^{46}$ claim. The conditioned Fuji Ortho LC group had a cohesive bond failure, yet this group's shear bond strength was significantly ( $p<0.001)$ weaker than the Transbond control and moistened Ultra Band Lok which had adhesive bond failures (0.84).

There appears to be a lack of standardization in in-vitro bonding protocols making inter-study evaluation and comparison difficult. ${ }^{43,45}$ The limitations for interpreting and comparing results from other studies comes mainly from three areas: (a) the environmental stressing of material, (b) sample size, and (c) bond strength units. Stress testing by thermocycling has been shown to reduce bond strength. Supak and Burgess ${ }^{29}$ found thermocycling to decrease the bond strengths of their sample of GICs by nearly $50 \%$. In the present study, the sample was thermocycled on the premise that by exposing the specimens to a simulated environmental stress this would allow a more accurate comparison to a clinical situation. $^{3}$ Fox et als stated that at least 20 and preferably 30 specimens should be used per test and bond strengths reported in megapascals. ${ }^{43,45}$

The suggested advantages that the resin modified GICs provide include: (a) the ability to be used in a moist environment without etching, (b) the provision of localized fluoride release, (c) the attribute of sufficient bond strength, and (d) the capacity for removal without 
damage to the undertying enamel. From the current study, the Fuji Ortho LC did not provide an adequate bond strength without the use of an enamel conditioner prior to placement of the cement. This new generation of resin modified GICs show improved bond strength over the previous GICs. In the current study there may be some controversy as to whether two GICs were compared. Although Ultra Band Lok is considered a glass ionomer cement, its chemical makeup suggests that it is a composite filled with glass ionomer powder or compomer. At the present time, a system where only a chemical bond of adhesive to enamel is used does not provide a bond strength sufficient to keep orthodontic brackets from debonding from posterior teeth. However, the present study suggests that the addition of a mechanical bond through enamel conditioning to the chemical bond may provide a clinically acceptable bond strength. 


\section{SUMMARY AND CONCLUSTONS}

A total of 200 human premolar teeth were used to bond orthodontic brackets using two glass ionomer cements and a composite control. The findings were as follows:

1. Ultra Band Lok, when used concurrently with its 3 second conditioner and hydrophilic sealant, achieved an in vitro shear bond strength similar to the composite control.

2. The Fuji Ortho LC glass ionomer system should be used concurrently with $10 \%$ polyacrylic acid to enhance its bond strength to a clinically acceptable level.

3. The Fuji Ortho LC without enamel conditioning prior to bonding showed inadequate bond strength.

4. The nonconditioned Fuji Ortho LC, the moisture contaminated Ultra Band Lok, and the Transbond control had mean ARI values of less than one indicating fracture site principally at the enamel/adhesive interface.

5. The regular Ultra Band Lok and the conditioned Fuji Ortho LC had mean ARI values of 1.62 and 1.44 respectively indicating fracture sites principally within the adhesive. 


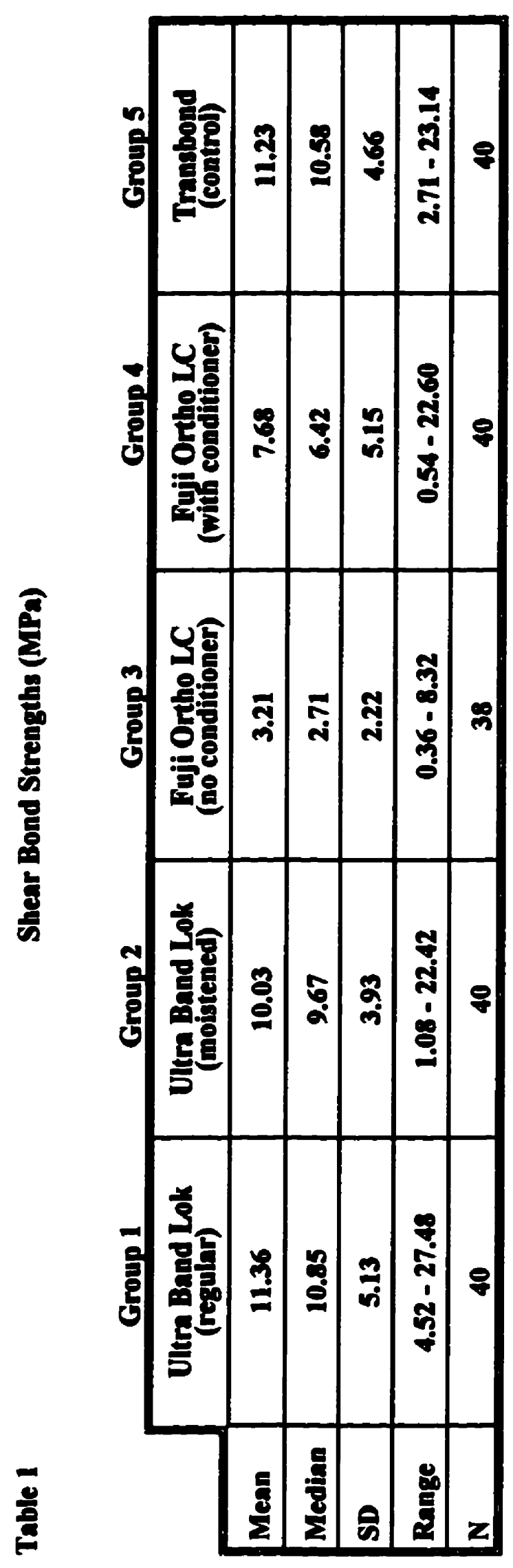




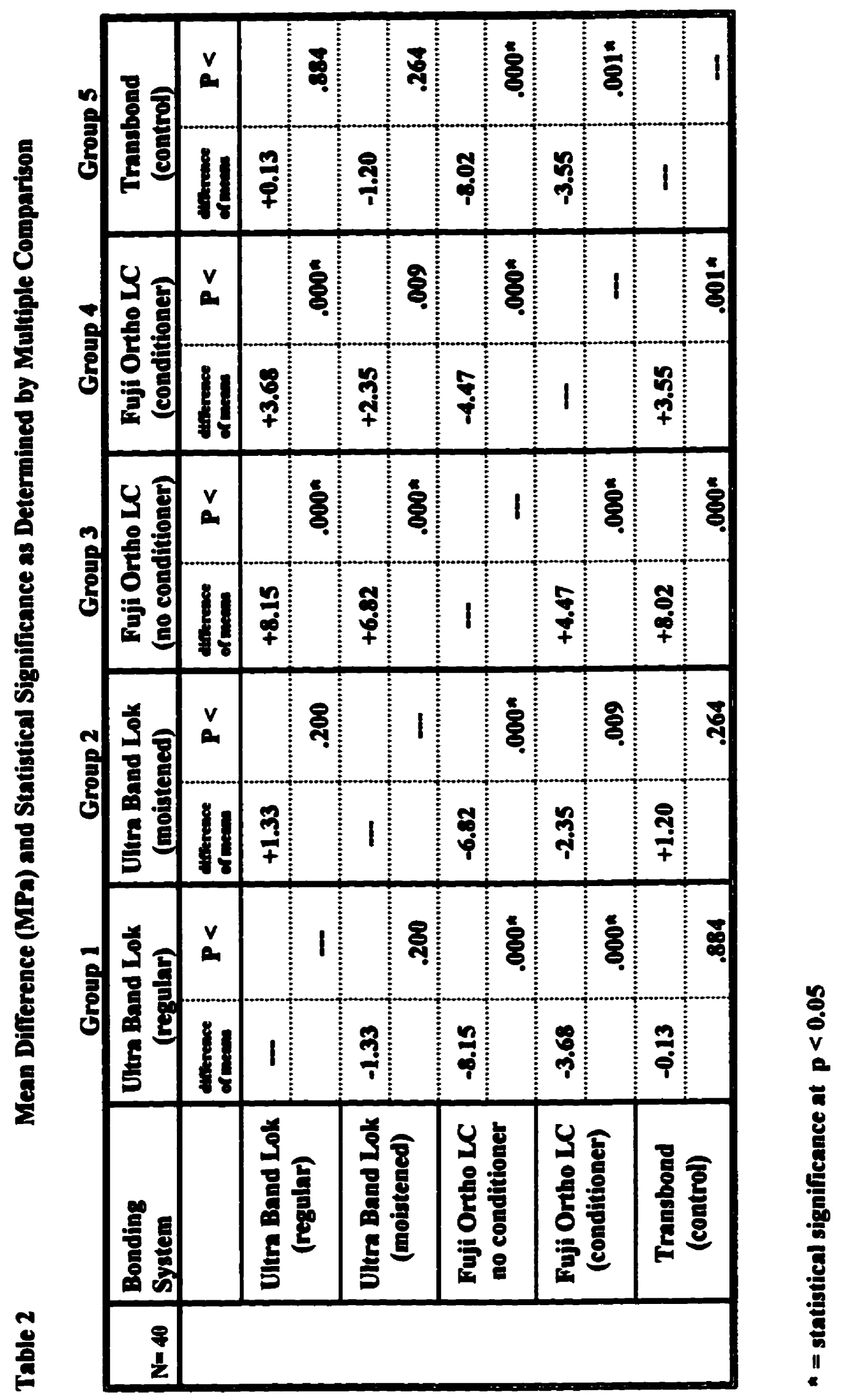




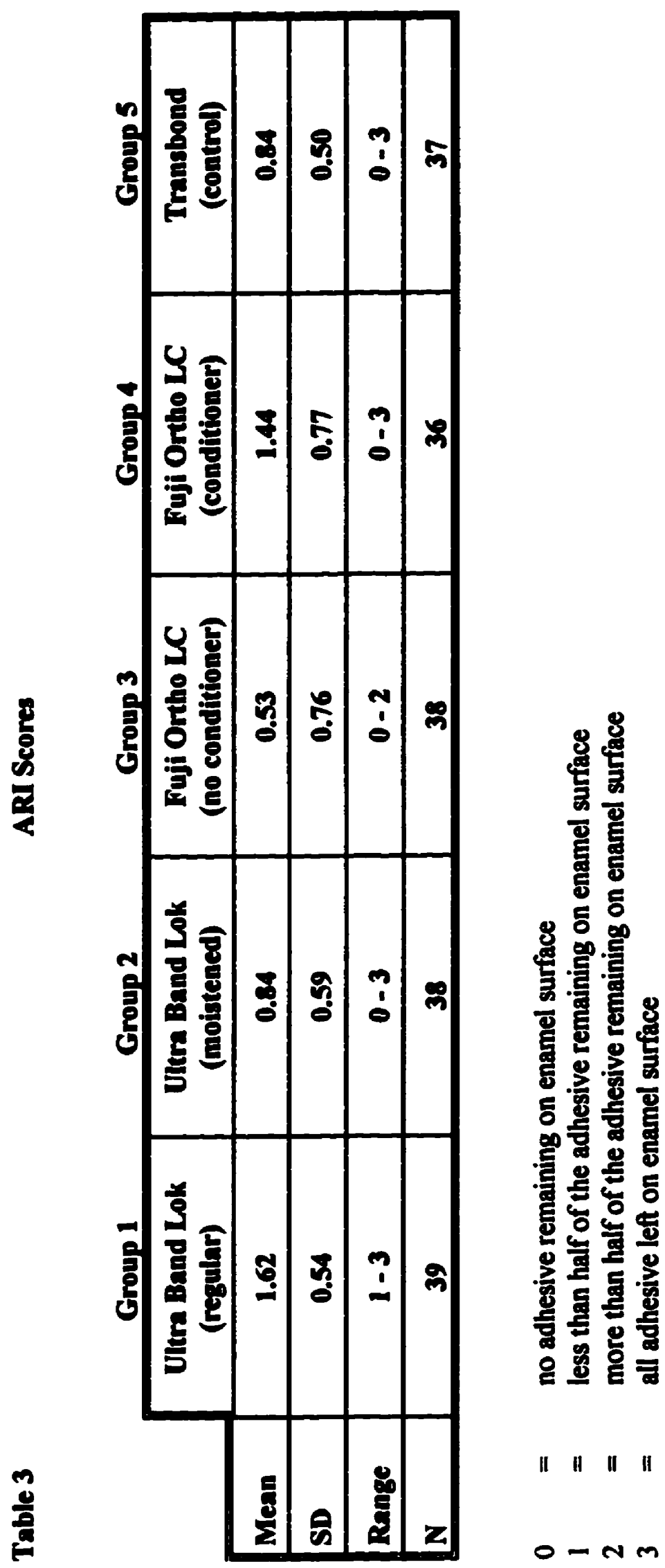




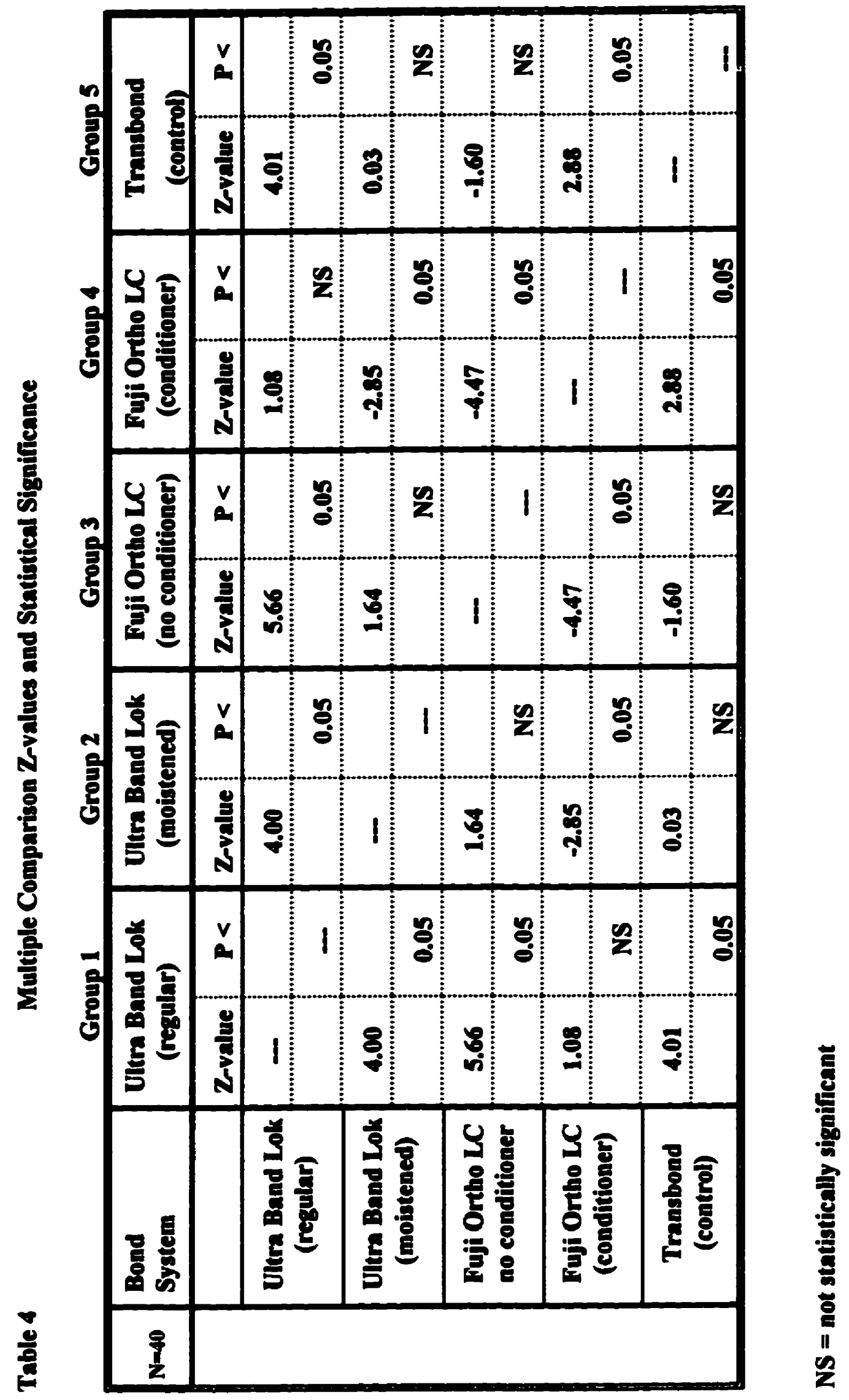




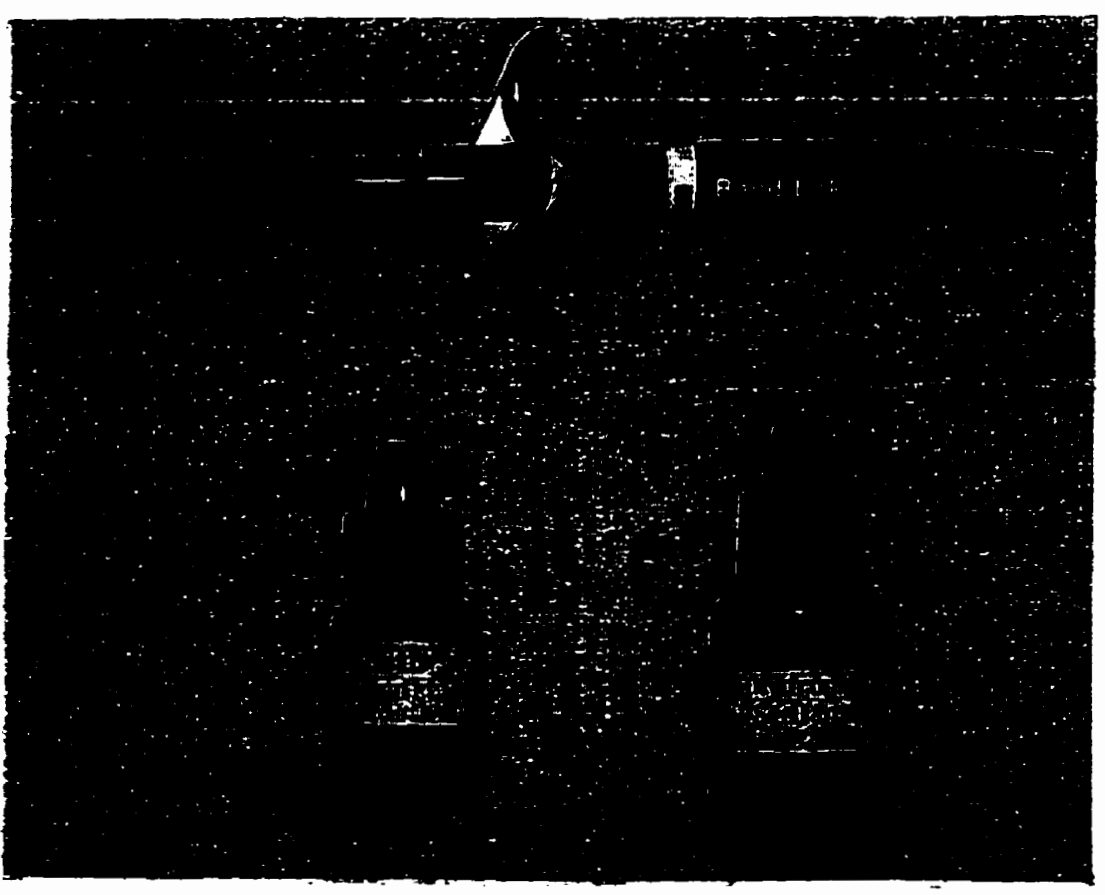

Figure 1

Ultra Band Lok glass ionomer cement

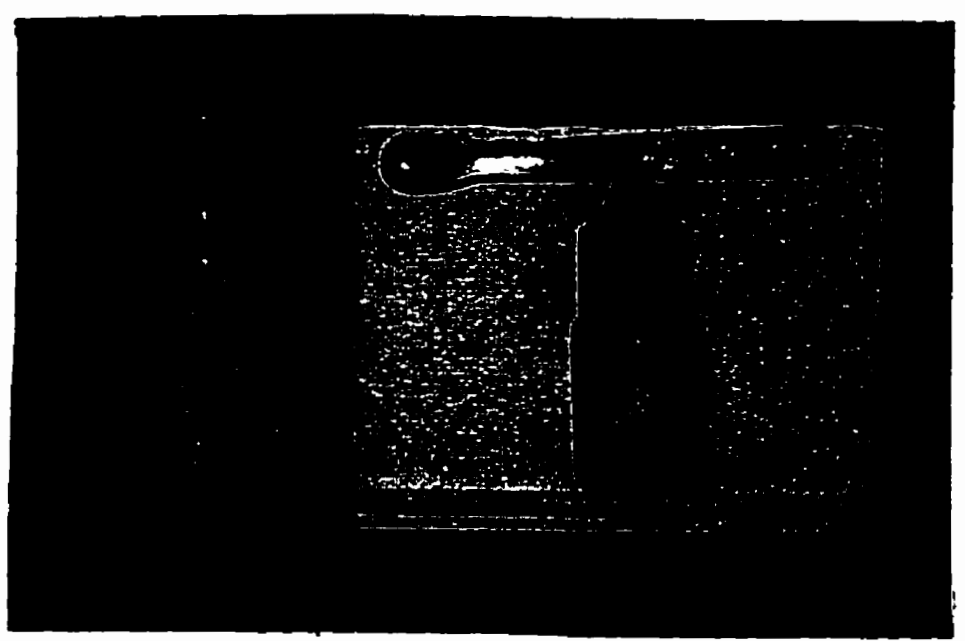

Figure 2

Fuji Ortho LC glass ionomer cement 


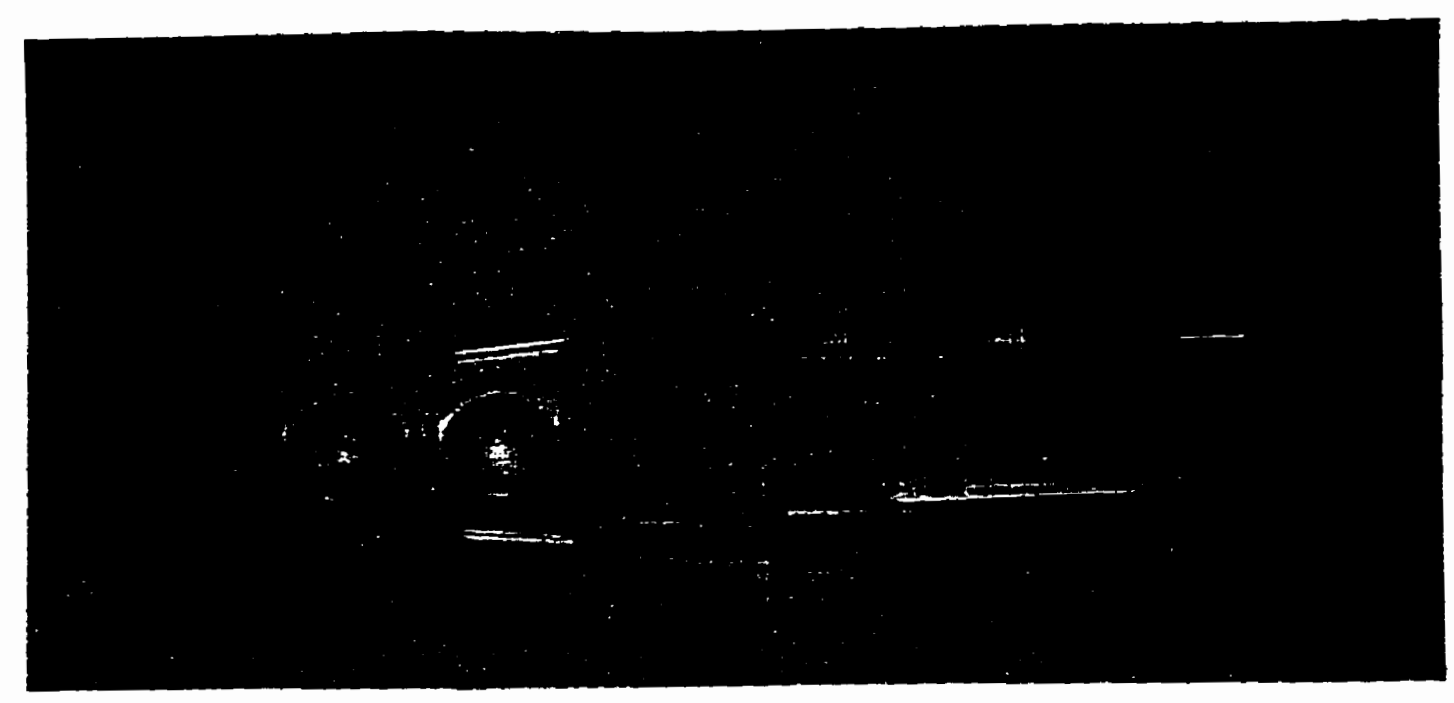

Figure 3

Transbond orthodontic bonding material

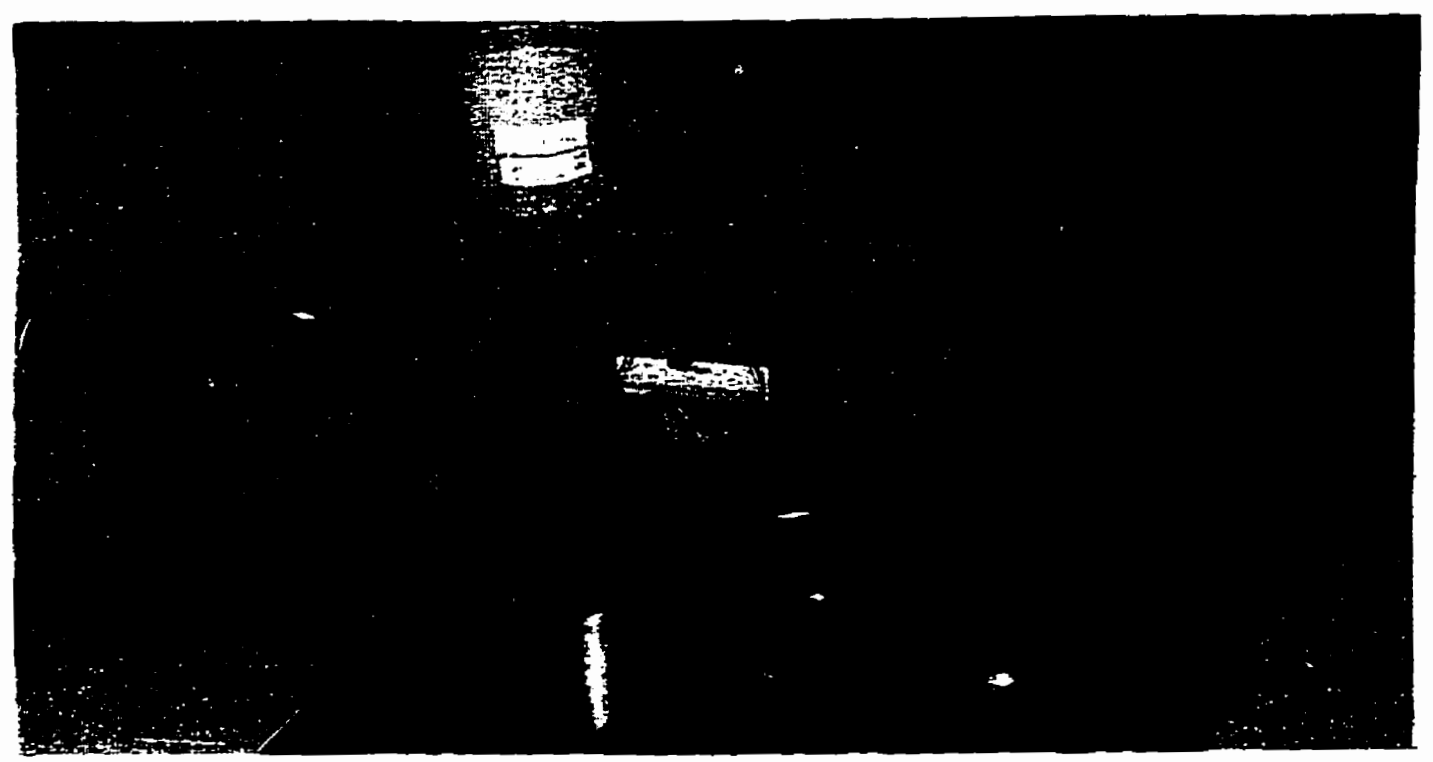

Figure 4

A sample placed in the Thermocycle unit 


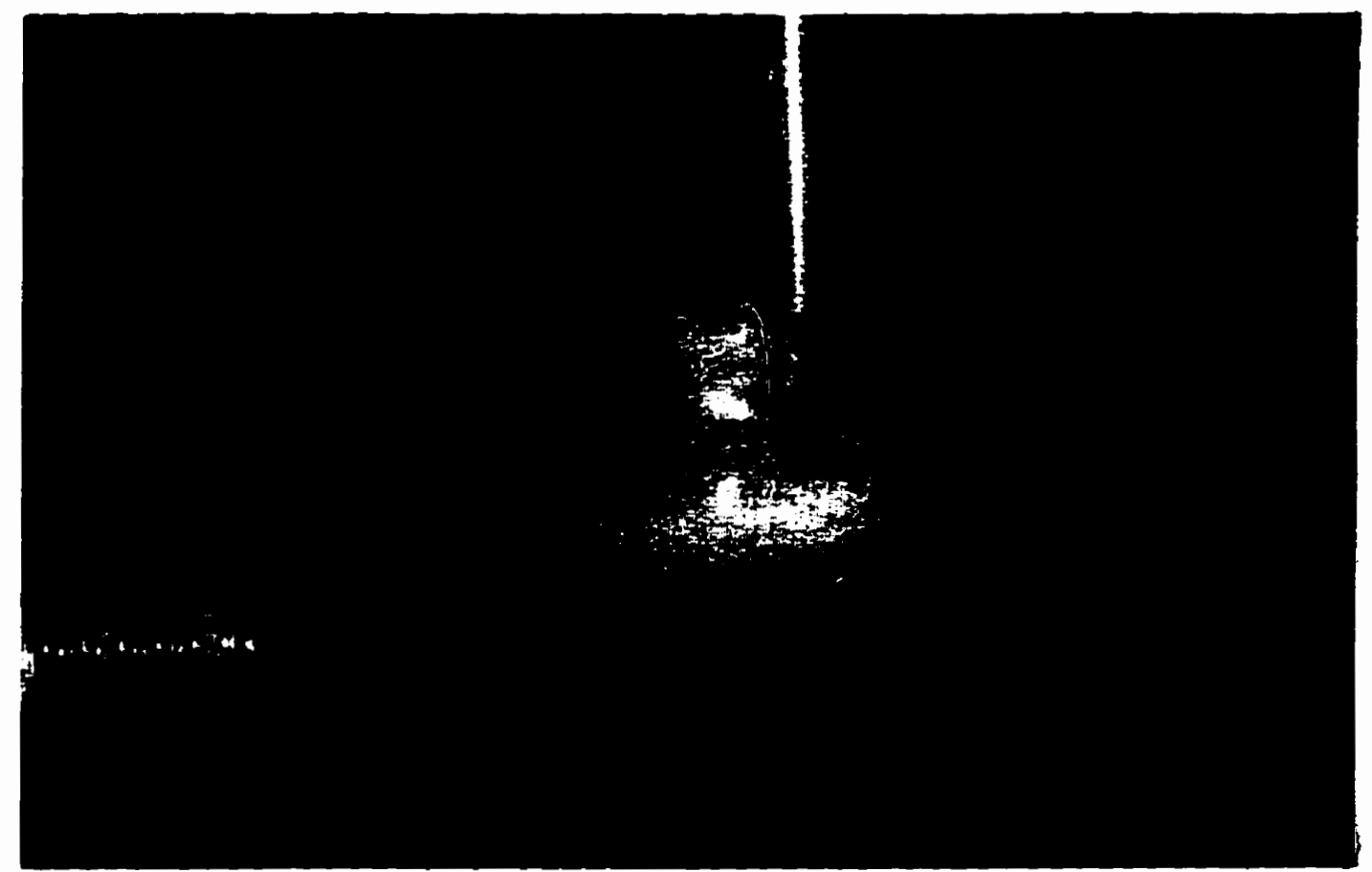

Figure 5

Premolar tooth with bonded bracket in an acrylic block secured in vice

Note: the plunger of Instron machine is

perpendicular to bracket 
Figure 6

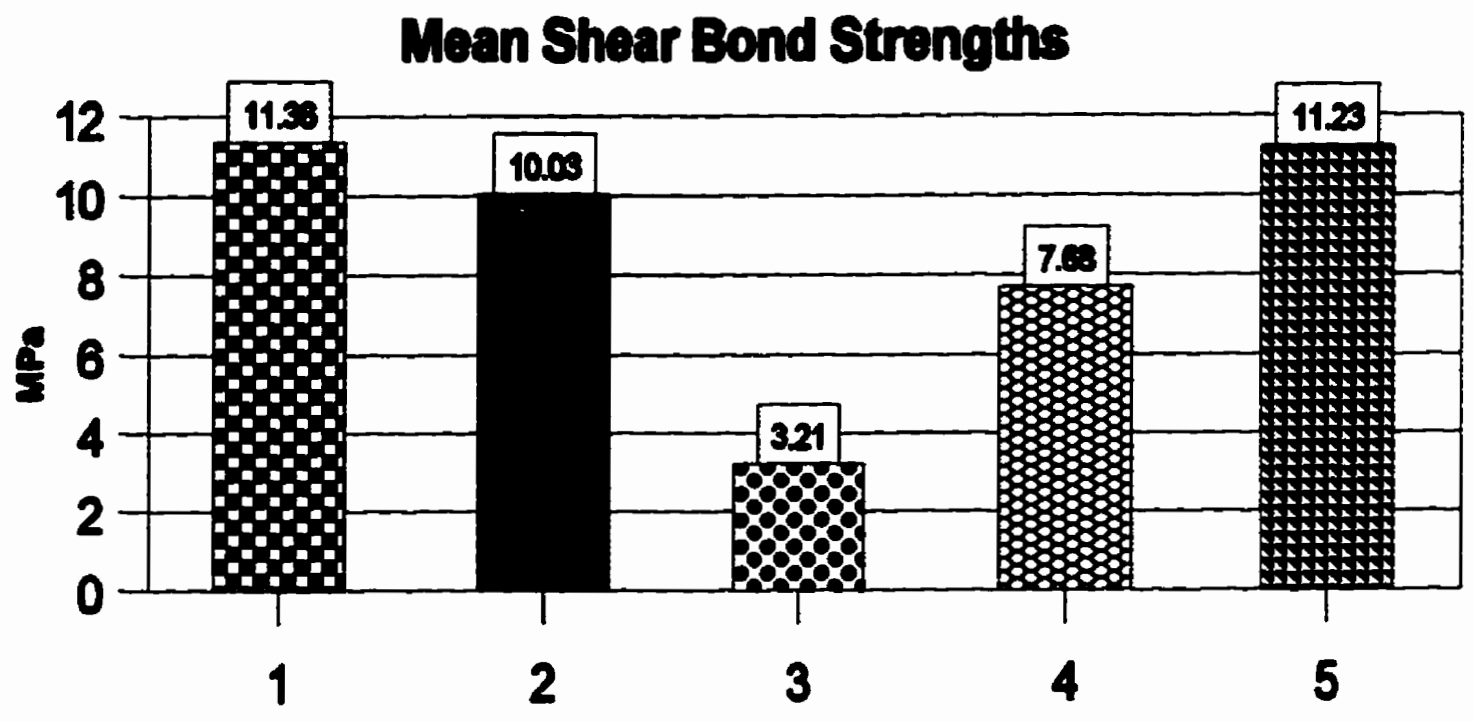

Ultra Band Lok (regular)

Ultra Band Lok (moistened)

Fuji Ortho LC (no conditioner)

Fujf Ortho LC (conditioner)

Transbond (control) 
Pigure 7

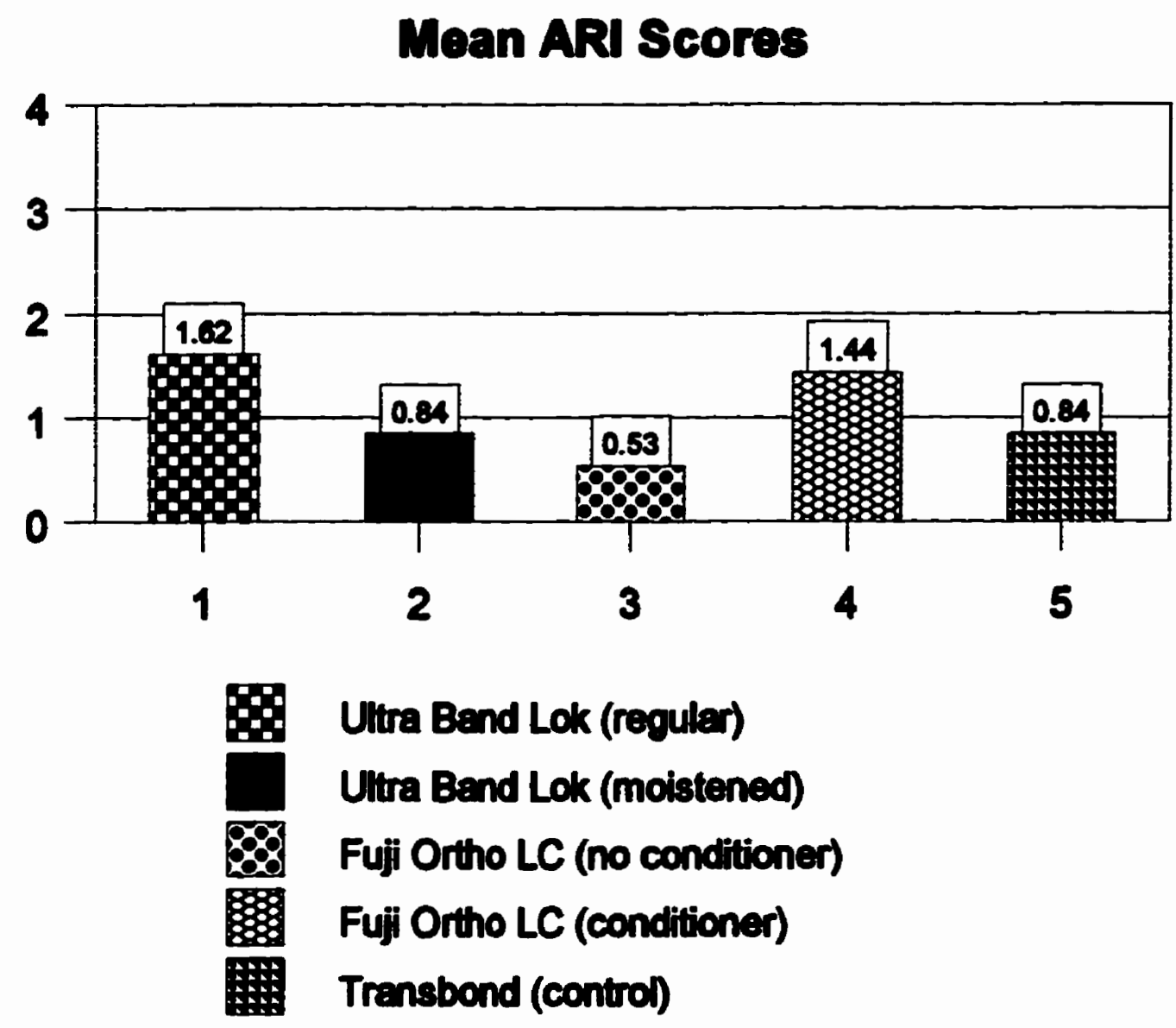




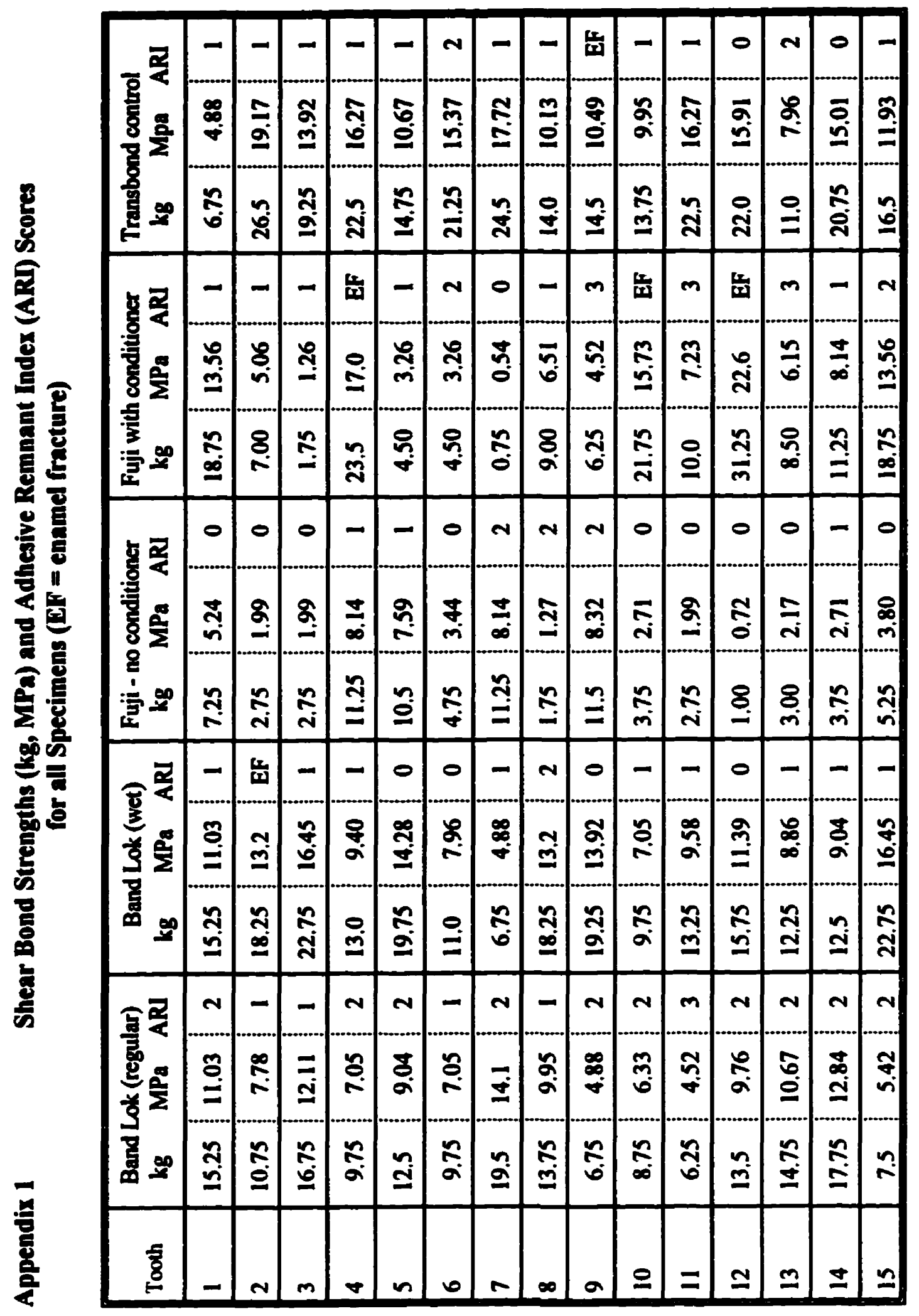




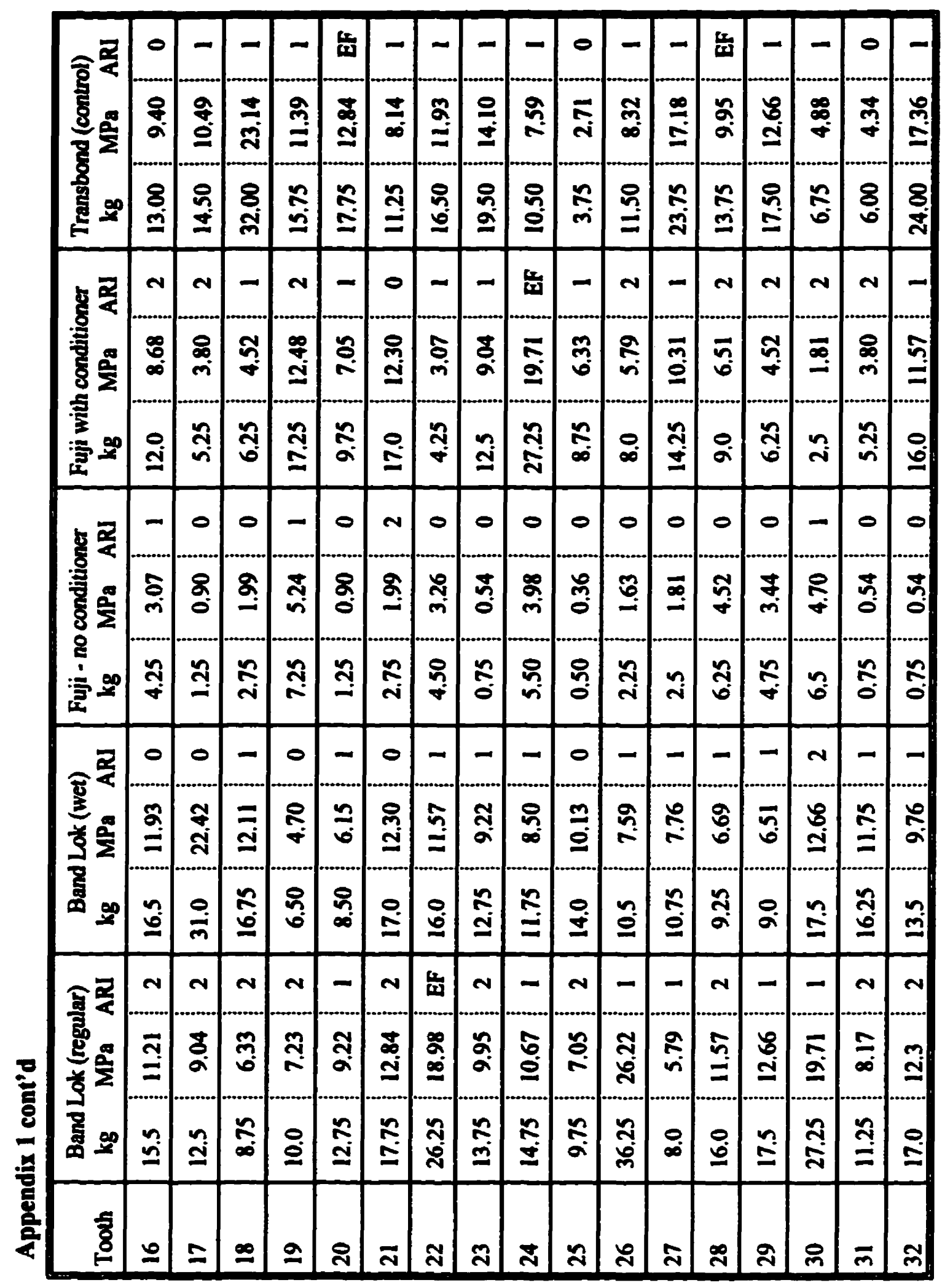




\begin{tabular}{|c|c|c|c|c|c|c|c|c|}
\hline \multirow{3}{*}{ 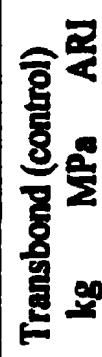 } & - & - & - & - & 0 & 0 & 0 & - \\
\hline & 文 & $\frac{n}{6}$ & $\underset{n}{\stackrel{9}{n}}$ & $\stackrel{a}{\stackrel{m}{z}}$ & $\stackrel{m}{g}$ & $\underset{ \pm}{ \pm}$ & జ్త్రి & 웅 \\
\hline & જ̆ & $\underset{\infty}{\infty}$ & 8 & $\frac{n}{n}$ & $\underset{\square}{\mathbb{S}}$ & 오 & $\frac{8}{\not+}$ & $\begin{array}{l}\mathcal{8} \\
\dot{m}\end{array}$ \\
\hline \multirow{3}{*}{ 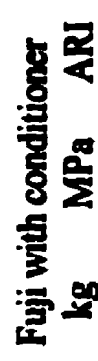 } & $N$ & $=$ & - & $N$ & - & 0 & $N$ & \\
\hline & $\underset{m}{s}$ & $\stackrel{0}{7}$ & $\stackrel{2}{n}$ & $\frac{N}{N}$ & $\underset{\tilde{\sigma}}{\tilde{n}}$ & $\stackrel{R}{R}$ & $\underset{m}{\mathcal{O}}$ & ตู \\
\hline & $\underset{7}{7}$ & $\frac{n}{n}$ & $\begin{array}{l}\text { 오 } \\
\text { อ }\end{array}$ & $\underset{m}{8}$ & \& & $\stackrel{2}{\stackrel{5}{\varrho}}$ & $\underset{\infty}{8}$ & $\underset{\infty}{a}$ \\
\hline \multirow{3}{*}{ 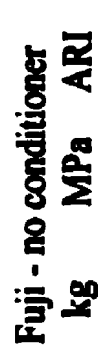 } & - & $N$ & 0 & 0 & $N$ & - & 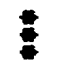 & $E$ \\
\hline & $\underset{8}{R}$ & $\underset{\text { mi }}{\text { m }}$ & 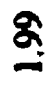 & $\underset{i}{a}$ & $\underset{\text { nุ }}{\mathbb{Z}}$ & ${ }_{n}^{8}$ & $=$ & $=$ \\
\hline & ஜึ & $\frac{8}{8}$ & $\frac{n}{i}$ & $\underset{m}{8}$ & $\stackrel{\sim}{\sim}$ & 8 & 8 & $E$ \\
\hline \multirow{3}{*}{ 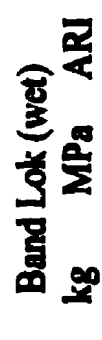 } & - & $N$ & - & - & $N$ & 学 & 0 & - \\
\hline & $\stackrel{n}{a}$ & $\underset{\infty}{\sim}$ & 5。 & $\stackrel{\circ}{m}$ & $\frac{2}{a}$ & $\stackrel{n}{n}$ & $g$ & 8 \\
\hline & 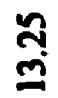 & $\stackrel{ }{\beth}$ & $\underset{j}{\stackrel{n}{ \pm}}$ & $\underset{\infty}{\infty}$ & ஜ̆ & $\underset{n}{\stackrel{n}{n}}$ & \& & $\frac{n}{a}$ \\
\hline \multirow{3}{*}{ 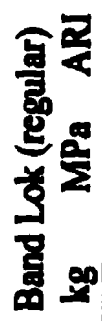 } & - & $N$ & - & - & $N$ & - & - & - \\
\hline & $\bar{a}$ & స్తి & $\overline{\bar{N}}$ & ช్ర & $\cong$ & $\stackrel{\infty}{\underset{\sim}{N}}$ & $\stackrel{g}{=}$ & 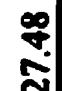 \\
\hline & $\begin{array}{l}8 \\
\text { న్ }\end{array}$ & $\underset{\infty}{\stackrel{0}{0}}$ & $\frac{n}{0}$ & $\frac{n}{2}$ & స్ & 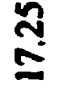 & $\frac{n}{n}$ & ర్ \\
\hline & $\tilde{m}$ & m & $\stackrel{n}{m}$ & ஜூ & $\bar{m}$ & $\stackrel{\infty}{\infty}$ & ह & $F$ \\
\hline
\end{tabular}




\section{RUFURNACES}

1. Buonocore MG. A simple method of increasing the adhesion of acrylic filling materials to enamel surface. J Dent Res 1955;34:849-53.

2. Newman GV. Epoxy adhesives for orthodontic attachments: progress report. Am J Orthod 1965;51:901-12.

3. Reynolds $\mathbb{R}$, von Fraunhofer JA. Direct bonding of orthodontic attachments to teeth: The relation of adhesive bond strength to gauze mesh size. Br J Orthod 1976;3:9195.

4. Proffit WR, Fields HW, Nixon WL. Occlusal forces in normal and long-face adults. J Dent Res 1983;62:566-74.

5. Maijer R, Smith DC. A new surface treatment for bonding. J Biomed Mater Res 1979;13:975-85.

6. Gange P, Phillips HW. JCO Interviews: Paul Gange on the present state of bonding. JCO 1995;29:429-36.

7. Reynolds IR A review of direct orthodontic bonding. Br J Orthod 1979;2:171-78.

8. Silverstone LM. The acid etch technique: in vitro studies with special reference to the enamel surface and the enamel-resin interface. In Silverstone LM, Dogon L, editors: Proceedings of an international symposium on the acid etch technique, St Paul, Minn, 1975, North Central.

9. Diedrich P. Enamel alterations from bracket bonding and debonding: $\mathbf{A}$ study with the scanning electron microscope. Am J Orthod 1981;79:500-22.

10. Fitzpatrick DA, Way DC. The effects of wear, acid etching, and bond removal on human enamel. Am J Orthod 1977;72:671-81.

11. Brown CRL and Way DC. Enamel loss during orthodontic bonding and subsequent loss during removal of filled and unfilled adhesives. Am J Orthod 1987;74:663-71.

12. Pus MD, Way DC. Enamel loss due to orthodontic bonding with filled and unfilled resins using various clean-up techniques. Am J Orthod 1980;77:269-83.

13. Zachrisson BU, Skogan O, Hoymyhr S. Enamel cracks in debonded, debanded and orthodontically untreated teeth. Am J Orthod 1980;77:307-19. 
14. Ogaard B, Rolla G, Arends J. Orthodontic appliances and enamel demineralization, Part 1: Lesion development. Am J Orthod 1988;94:68-73.

15. Gorlick L, Geiger AM, Gwinnett AJ. Incidence of white spot formation after bonding and banding. Am J Orthod 1982;81:93-8.

16. Voss A, Hickel R, Mollner S. In vivo bonding of orthodontic brackets with glass ionomer cement. Angle Orthod 1993;63:149-53.

17. Hallgren A, Oliveby A, Twetman S. Fluoride concentration in plaque adjacent to orthodontic brackets retained with glass jonomer cements. Br J Orthod 1994;21:2326.

18. Hallgren A, Oliveby A, Twetman S. $\mathrm{L}(\mathrm{t})$-Lactic acid production in plaque from orthodontic appliances retained with glass ionomer cements. Caries Res 1993;27:5154.

19. Ostman-Andersson E, Marcusson A, Horstedt P. Comparative SEM studies of the enamel surface following the use of glass ionomer cement and a diacrylate resin for bracket bonding. Swed Dent J 1993;17:139-46.

20. Klockowski R, Davis EL, Joynt RB, Wieczkowski G, McDonald A. Bond strength and durability of glass ionomer cements used as bonding agents in the placement of orthodontic brackets. Am J Orthod Dentofac Orthop 1989;96:60-4.

21. Cook PA, Youngson CC. An in vitro study of bond strength of glass ionomer cement in the direct bonding of orthodontic brackets. Br J Orthod 1988;15:247-53.

22. Fajen VB, Duncanson MG, Nanda RS, Currier GF, Angolkar PV. An in vitro evaluation of bond strength of three glass ionomer cements. Am J Orthod Dentofac Orthop 1990;97:316-22.

23. Wiltshire WA. Shear bond strengths of a glass ionomer for direct bonding in orthodontics. Am J Orthod Dentofac Orthop 1994;106:127-30.

24. Miquel JAM, Almeida MA, Chevitarese O. Clinical comparison between a glass ionomer cement and a composite for direct bonding of orthodontic brackets. Am J Orthod Dentofac Orthop 1995;107:484-87.

25. Miller JR, Mancl L, Arbuckle G, Baldwin J, Phillips RW. A three-year clinical trial using a glass ionomer cement for the bonding of orthodontic brackets. Angle Orthod 1996;66:309-12. 
26. Fricker JP. A 12-month clinical evaluation of a light-activated glass polyalkenoate (ionomer) cement for the direct bonding of orthodontic brackets. Am J Orthod 1994;105:502-05.

27. Silverman E, Cohen M, Demke $\mathbf{R}$, Silverman $\mathbf{M}$. A new light-cured glass ionomer cement that bonds brackets to teeth without etching in the presence of saliva. Am J Orthod 1995; 108:231-36.

28. Joseph VP, Harris AMP, Grobler SR. Bond strength of orthodontic brackets using a new glass ionomer (abstr.). J Dent Res 1994;73 (special issue):197.

29. Supak LA, Burgess JO. Shear bond strength of orthodontic brackets bonded with four cements (abstr.). J Dent Res 1994;73 (special issue):413.

30. Kao EC, Rezvan E, Eliades T, Johnson WM Debond shear force of light-cured glass ionomer cements (abstr.). J Dent Res 1994;73 (special issue):413.

31. Ewoldsen N, Beatty MW, Erickson L, Feely D. Effects of enamel conditioning on bond strength with a restorative light-cured glass ionomer. J Clin Orthod 1995;29:621-24.

32. O'Reilly MM, Featherstone JDB. Demineralization and remineralization around orthodontic appliances: An in vivo study. Am J Orthod Dentofac Orthop 1987;92:3340.

33. Hotz P, Mclean JW, Sced I, Wilson AD. The bonding of glass ionomer cements to metals and tooth substrates. Brit Dent J 1977;142:41-47.

34. David S. Fluoride uptake from a glass ionomer cement used as an orthodontic bracket adhesive. Brit J Orthod 1994;21:117.

35. White LW. Glass ionomer cement. J Clin Orthod 1986;20:387-91.

36. Personal communication with Mr. Paul Gange. 1996.

37. Personal communication with Dr. Richard Demke. 1996.

38. Jaochakarasiri P, Techasombooranakit $K$, Nathanson D, Gianelly A, Giordano R. Shear bond strength of glass ionomer bonded orthodontic brackets (abstr). J Dent Res 1995;74:461.

39. Mitchell CA, O'Hagan E, Walker JM. Probability of failure of orthodontic brackets bonded with glass-ionomer or composite cement (abstr). J Dent Res 1995;74:896. 
40. Carter NE, McCabe JF. Laboratory studies of a dual-cured glass-ionomer cement as an orthodontic bonding agent (abstr). 1995;74:852.

41. Scott GG, Garcia-Godoy F, Summitt JB. Shear bond strength of brackets bonded with glass ionomers (abstr). 1995;74:187.

42. Shin KS, Lee KS. The efiects of surface treatments on shear bond strengths of lightcured and chemically cured glass ionomer cements to enamel (abstr). 195;74:991.

43. Millett DT, McCabe JF. Othodontic bonding with glass ionomer cement - a review. Eur J Orthod 1996;18:385-99.

44. Nollie G, Foley TF, McConnell RJ. Orthodontic Bonding to Adlloy Treated Type IV Gold. Accepted for publication by Angle Orthod 1997.

45. Fox N, MoCabe JF, Buckley JG. A critique of bond strength testing in orthodontics. Brit J Orthod 1994;21:33-43.

46. Matasa CG. Adhesion and its ten commandments. Am J Orthod 1989;95:355-56.

47. Artun J, Bergland S. Clincial trials with crystal growth conditioning as an alternative to acid-etch pretreatment. Am J Orthod 1984;85:333-40.

48. Wilson AD, Prosser HJ, Powis DM. Mechanism of adhesion of polyelectrolyte cements to hydroxyapatite. J Dent Res 1983;62:590-92. 